\title{
The perfused swine uterus model: long-term perfusion
}

\author{
Klaudija Geisler, Julian Künzel, Philipp Grundtner, Andreas Müller, Matthias W Beckmann and Ralf Dittrich*
}

\begin{abstract}
Background: It has previously been shown that the viability of swine uteri can be maintained within the physiological range in an open perfusion model for up to 8 hours. The aim of this study was to assess mediumto long-term perfusion of swine uteri using a modified Krebs-Ringer bicarbonate buffer solution (KRBB) in the established open perfusion model.

Methods: In an experimental study at an infertility institute, 30 swine uteri were perfused: group 1: $n=11, K R B B$; group 2: $n=8$, modified KRBB with drainage of perfusate supernatant; group 3: $n=11$, modified KRBB with drainage of perfusate every $2 \mathrm{~h}$ and substitution with fresh medium. Modified and conventional KRBB were compared with regard to survival and contraction parameters: intrauterine pressure (IUP), area under the curve (AUC), and frequency of contractions (F).

Results: Modified KRBB showed significantly higher IUP, AUC, and $F$ values than perfusion with conventional KRBB. In group 3, the organ survival time of up to $17 \mathrm{~h}$, with a $98 \%$ rate of effective contraction time, differed significantly from group $1(P<0.001)$.

Conclusions: Using modified KRBB in combination with perfusate substitution improves the open model for perfusion of swine uteri with regard to survival time and quality of contraction parameters. This model can be used for medium- to long-term perfusion of swine uteri, allowing further metabolic ex vivo studies in a cost-effective way and with little logistic effort.
\end{abstract}

Keywords: Swine uterus, Perfusion, Long-term, Survival, Perfusion model

\section{Background}

Experimental organ perfusion originated in the field of transplantation medicine, where it was used to investigate physiological, pathophysiological, and metabolic processes in tissue and cells [1-3]. Studies of the liver, lungs, and kidney using long-term perfusion have been successfully carried out and reported $[2,4,5]$. Various perfusion solutions have been used for organ maintenance; Iwasaki et al., for example, used a Krebs-Henseleit-Ringer medium for long-term perfusion of isolated rat hearts [6].

In 1986, Bulletti et al. developed an open extracorporeal perfusion system, without recirculation of the medium, for the human uterus $[7,8]$. They carried out various in vitro studies on extirpated uteri, such as hormonal analyses in the endometrium and myometrium and assessment of electromechanical activity in the smooth muscle. They also

\footnotetext{
* Correspondence: ralf.dittrich@gyn.imed.uni-erlangen.de

Department of Gynecology, Erlangen University Hospital, Erlangen, Germany
}

examined hormonal influences on uterine contractility during different phases of the menstrual cycle $[9,10]$. The first early human pregnancy in a perfused uterus was achieved in 1987 [8]. On the basis of the developments by Bulletti et al., Dittrich and Maltaris in 2003 established a model for the perfusion of swine uteri [11]. The use of swine uteri in the perfusion model is suitable for investigating the effects of a wide variety of medications in large numbers of organs in physiological conditions. The results are well comparable with human conditions. Although there are anatomic and physiological differences between the human and swine uterus, the microscopic structures of the organs are similar. The regulatory control system for endocrine functions also allows direct comparison. It was shown in these studies that vitality parameters could be maintained within the physiological range for up to 8 hours in optimal experimental conditions [11].

\section{Biomed Central}

(c) 2012 Geisler et al.; licensee BioMed Central Ltd. This is an Open Access article distributed under the terms of the Creative Commons Attribution License (http://creativecommons.org/licenses/by/2.0), which permits unrestricted use, distribution, and reproduction in any medium, provided the original work is properly cited. 
Topics investigated using the swine uterus perfusion model have included the influence of oxytocin, by Dittrich et al. [11]; the roles of estrogen, progesterone [12], and prostaglandins, by Müller et al. [13]; and the effect of spasmolytics on contractility in the swine uterus, by Künzel et al. [14]. The model has also been used to analyze the mechanisms of intrauterine transport towards the dominant follicle [15]. Richter et al. [16] published the results for long-term perfusion using a closed perfusion model of the human uterus and with a modified Krebs-Ringer bicarbonate buffer (KRBB) solution in normothermia. A total of 25 human uteri were studied for up to 24 hours, with preservation of cell integrity and thus in physiological conditions. The use of a closed system, with recirculation of the medium, led to a marked reduction in the amount of perfusate required in comparison with the studies by Bulletti et al. As reported by Dittrich et al., the vitality of swine uteri can be maintained in an open perfusion model for up to $8 \mathrm{~h} \mathrm{[11].}$

The aim of the present study was to investigate medium-term to long-term perfusion of swine uteri using the established open perfusion model. In the future, it is intended to use the swine uterus in vitro to investigate more detailed physiological and metabolic issues, e.g. the role of $\mathrm{M}_{3}$ - cholinergic receptors. For this purpose, an experimental approach was used to compare a modified KRBB solution as described by Richter et al. [16] with conventional KRBB with regard to the survival period achievable in swine uteri.

\section{Methods}

\section{Swine uterus}

Swine uteri were collected from the abattoir in Erlangen in the early morning, immediately after killing (with electric shocks, $1.5 \mathrm{~A}, 400 \mathrm{~V}, 4 \mathrm{~s}$ ). The organs were all from healthy swine aged 5-18 months. One uterus per day was selected for the experiments on the basis of size, weight, general condition, and cannulability of the uterine arteries. Any experimental research that is reported in the manuscript has been performed with the approval of the ethics committee of the University of Erlangen- Nuremberg.

\section{Cannulation}

The selected uterus was dissected in a standardized way for cannulation. The uterine arteries were released from the surrounding connective tissue in the broad ligament of the uterus bilaterally as far as the adventitia. This was followed by cannulation of the arteries using 16-G Abbocaths, which were fixed in place using Vicryl 3-0 sutures (Ethicon Johnson \& Johnson International Inc., Brussels) (Figure 1). Correct positioning of the Abbocaths and patency of the uterine vascular system were checked using careful rinsing of the two arteries, each with $2.5 \mathrm{~mL} \mathrm{NaCl} 0.9 \%$. An intraarterial injection of a heparin solution $(2500 \mathrm{IU}$ in $5 \mathrm{~mL}$

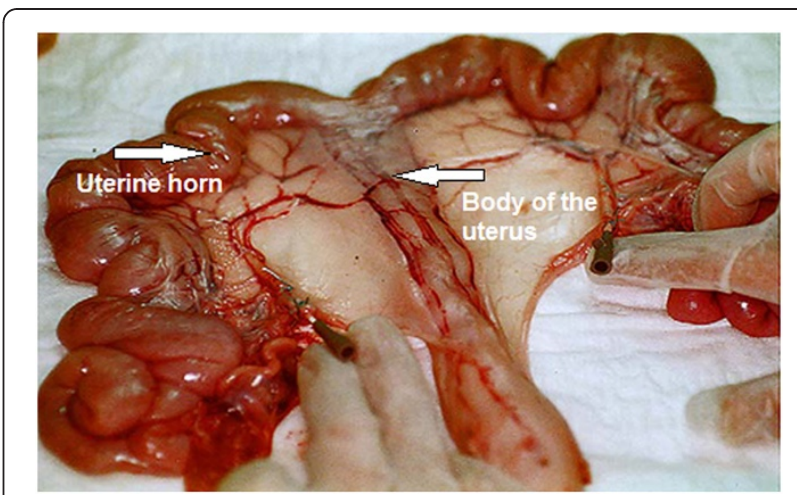

Figure $1 \mathrm{~A}$ bilaterally cannulated swine uterus (reproduced with permission from ref. 17).

$\mathrm{NaCl}$ 0.9\%; Braun Heparin Sodium 25000 IU vial; B. Braun Melsungen Ltd., Melsungen, Germany) was carried out to prevent thrombus formation and to rinse out any already coagulated blood. In addition, the tubes and the vascular plexus surrounding the ovary were ligated to prevent the perfusion solution from escaping at these points and to establish and maintain better uterine perfusion pressure. This was also intended to minimize any disturbing hormonal influences by estrogens and gestagens from the ovaries.

\section{Perfusion system}

Following cannulation, the organ that had been prepared for perfusion was placed in an organ bath at a set temperature. The organ bath initially consisted of $1 \mathrm{~L}$ of perfusion medium warmed to $37^{\circ} \mathrm{C}$. During the entire experiment, the temperature was kept constant at between $36.5^{\circ} \mathrm{C}$ and $37.5^{\circ} \mathrm{C}$ (temperature measurement probe, Raumedic; Rehau Ltd., Rehau, Germany). The perfusion medium was warmed to a constant $37^{\circ} \mathrm{C}$ in a shaking water bath and oxygenated with carbogen $\left(95 \% \mathrm{O}_{2}, 5 \%\right.$ $\mathrm{CO}_{2}$; Linde Inc., Frankfurt, Germany). The Abbocaths were connected with a silicon tube system. A roller pump (Heidolph Ltd., Kelheim, Germany) transported the medium in the tube system at a constant flow rate into the organ's arterial system. The flow rate was increased gradually over $10-15 \mathrm{~min}$ to approximately $15 \mathrm{~mL} / \mathrm{min}$. The perfusate flowed continuously through the uterus's open vascular system into the organ bath - i.e., there was no recirculation of the medium into the arterial system. The diagram in Figure 2 shows the experimental design.

\section{Perfusion medium}

\section{Krebs-Ringer bicarbonate buffer solution}

The physiological KRBB has been successfully used by Dittrich et al. and by Müller et al. since 2003 for experiments in the perfused swine uterus [11]. The solution is prepared in the institution in Erlangen in accordance 


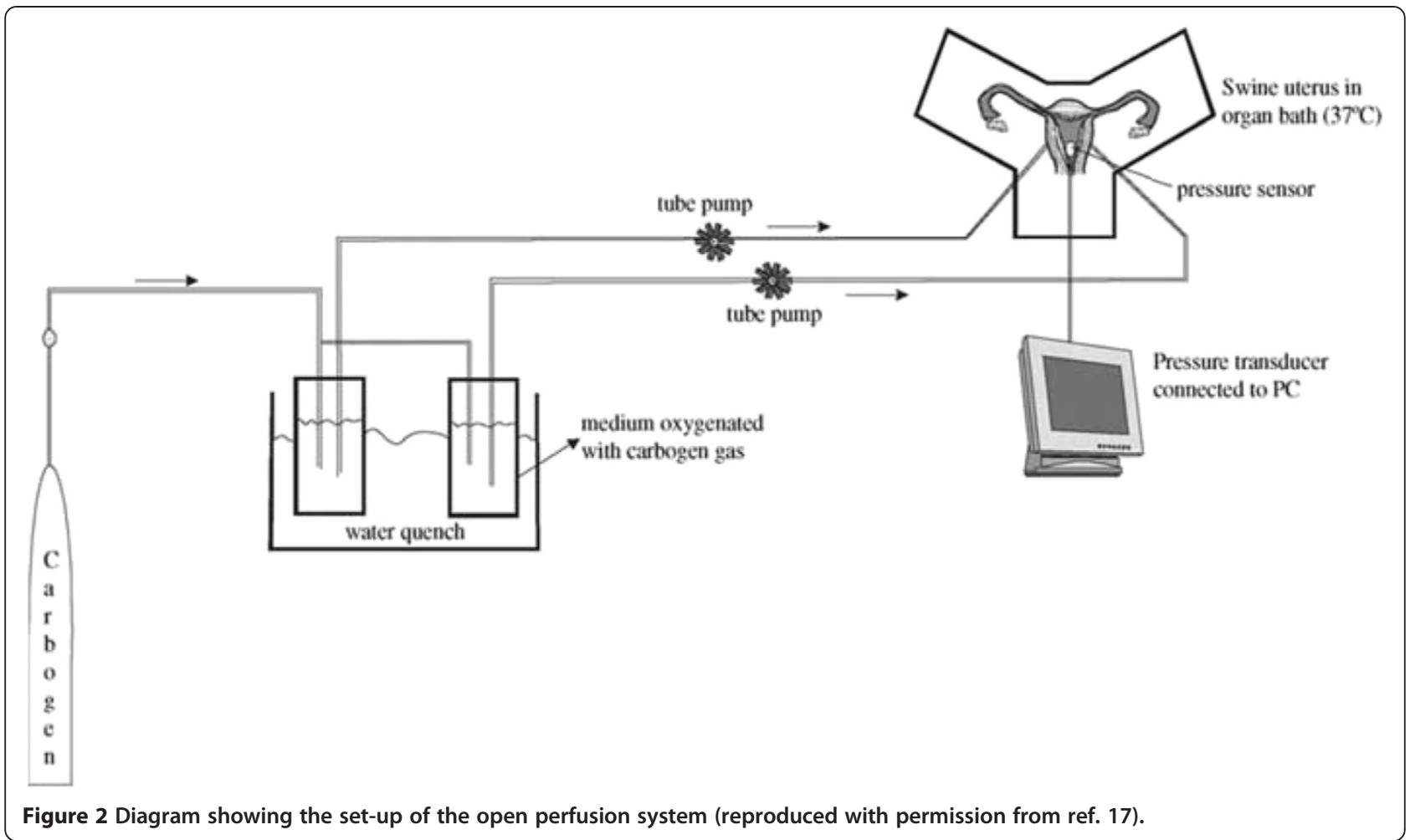

with instructions by the manufacturers Sigma-Aldrich Ltd. (Steinheim, Germany) (Table 1).

\section{Modified Krebs-Ringer bicarbonate buffer solution}

This perfusion solution, a modified form of KRBB, was previously used by Richter et al. for extracorporeal medium-term to long-term perfusion of human uteri with recirculation of the perfusate [16]. The vitality and functionality of the tissue was maintained for a period of up to $24 \mathrm{~h}$ with this solution [16-18]. The composition

Table 1 Quantities of substances required for singleconcentration solutions of the perfusion media used

\begin{tabular}{llll}
\hline \multicolumn{2}{l}{$\begin{array}{l}\text { Krebs-Ringer bicarbonate } \\
\text { buffer solution }\end{array}$} & \multicolumn{2}{l}{$\begin{array}{l}\text { Modified Krebs-Ringer } \\
\text { bicarbonate buffer solution }\end{array}$} \\
\hline $\mathrm{NaCl}$ & $7.00 \mathrm{~g} / \mathrm{L}$ & $\mathrm{NaCl}$ & $6.896 \mathrm{~g} / \mathrm{L}$ \\
\hline $\mathrm{KCl}$ & $0.34 \mathrm{~g} / \mathrm{L}$ & $\mathrm{KCl}$ & $0.372 \mathrm{~g} / \mathrm{L}$ \\
\hline $\mathrm{MgCl}$ & $0.05 \mathrm{~g} / \mathrm{L}$ & $\mathrm{MgSO}_{4}+\mathrm{H}_{2} \mathrm{O}$ & $0.246 \mathrm{~g} / \mathrm{L}$ \\
\hline $\mathrm{CaCl}+2 \mathrm{H}_{2} \mathrm{O}$ & $0.05 \mathrm{~g} / \mathrm{L}$ & $\mathrm{CaCl}_{2}+6 \mathrm{H}_{2} \mathrm{O}$ & $0.547 \mathrm{~g} / \mathrm{L}$ \\
\hline $\mathrm{Na}_{2} \mathrm{HPO}_{4}$ & $0.10 \mathrm{~g} / \mathrm{L}$ & $\mathrm{KH}_{2} \mathrm{PO}_{4}$ & $0.136 \mathrm{~g} / \mathrm{L}$ \\
\hline $\mathrm{NaHCO}_{3}$ & $1.26 \mathrm{~g} / \mathrm{L}$ & $\mathrm{NaHCO}_{3}$ & $2.305 \mathrm{~g} / \mathrm{L}$ \\
\hline $\mathrm{GluCOSe}_{+} \mathrm{H}_{2} \mathrm{O}$ & $1.98 \mathrm{~g} / \mathrm{L}$ & $\mathrm{D}-\mathrm{Glucose}$ & $1.500 \mathrm{~g} / \mathrm{L}$ \\
\hline $\mathrm{NaH}_{2} \mathrm{PO}_{4}+\mathrm{H}_{2} \mathrm{O}$ & $0.18 \mathrm{~g} / \mathrm{L}$ & Saccharose & $0.700 \mathrm{~g} / \mathrm{L}$ \\
\hline & & Glutathione & $0.050 \mathrm{~g} / \mathrm{L}$ \\
\cline { 3 - 4 } & & 1,4-Dithiothreitol & $0.100 \mathrm{~g} / \mathrm{L}$ \\
\cline { 2 - 4 } & & Regular insulin & $50 \mathrm{IU} / \mathrm{L}$ \\
\hline
\end{tabular}

of the modified solution (Table 1) ensured an isoosmolar ion concentration and an almost physiological $\mathrm{pH}$ value (7.36-7.44) and maintained a colloid osmotic pressure of approximately $24 \mathrm{mmHg}$ in the vessels. Saccharose, as an impermeable sugar, was used to prevent edema formation in the tissue. The tripeptide glutathione served as a reducing agent and radical scavenger [19]. Equilibrium between its reduced and oxidized forms was maintained using dithiothreitol. Regular insulin (Actrapid ${ }^{\circledR}$ HM NovoLet ${ }^{\circledR}$ $3 \mathrm{~mL} 100 \mathrm{IU} / \mathrm{mL}$ injection solution; Novo Nordisk Pharma, Ltd.) was also added to the perfusion medium to support metabolization of glucose. In contrast to the method described by Richter et al. [16], gentamicin (Refobacin) was not used. The agents were dissolved in $1 \mathrm{~L}$ of distilled water and well mixed in a shaking bath at $37^{\circ} \mathrm{C}$.

\section{Intrauterine pressure measurement}

Intrauterine pressure (IUP) was recorded using a doublechip microcatheter (Urobar 8 DS-F; Raumedic, Rehau Ltd., Rehau, Germany) (Figure 3). The measurement sensors were incorporated into the catheter at intervals of $8 \mathrm{~cm}$, so that after careful introduction, the distal sensor (IUP1) was positioned without tension in the one uterine horn and the proximal sensor in the body of the uterus (IUP2) (Figure 1). The pressure catheter was then fixed in place with a single button suture at approximately $11 \mathrm{~cm}$ to prevent it from sliding out during the measurements. After this, the pressure catheter was connected with the monitoring 


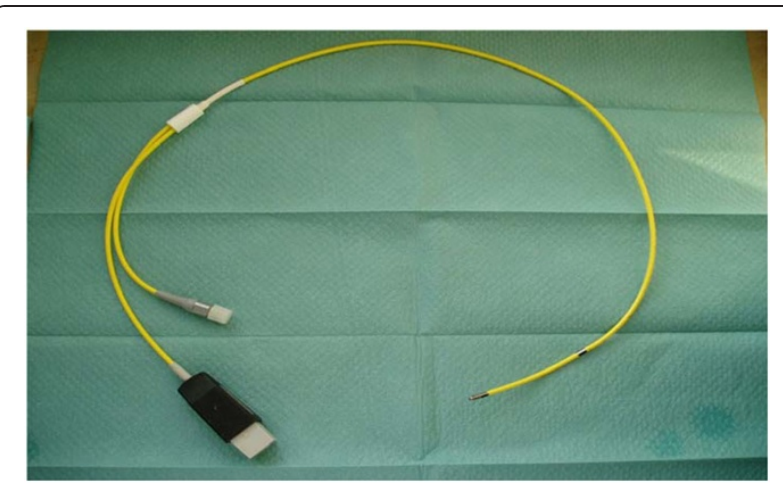

Figure 3 A double-chip microcatheter (Urobar 8 DS-F, Raumedic; Rehau \& Co. Ltd., Rehau, Germany).

device (Datalogger, MPR1; Raumedic, Rehau Ltd., Rehau, Germany) using a connecting cable.

The data logger allowed simultaneous recording of pressure changes at both measurement points (IUP1, IUP2) and continuous temperature measurement. A pressure value in millimeters of mercury was recorded by the Datalogger for each second. Pressure conditions in the vascular and tube system were displayed using a central venous pressure measurement module.

The measurement electrodes IUP1 and IUP2 and central venous pressure were calibrated to $0 \mathrm{mmHg}$ at the start of each experiment and the corresponding recording. The course of the experiment was observed on a graphic display and finally evaluated with the help of the corresponding software (Datalogg; Raumedic, Rehau Ltd., Rehau, Germany).

\section{Data processing and statistics \\ Data processing}

For each uterus, data for time intervals of $10 \mathrm{~min}$, $20 \mathrm{~min}$ after the start of the experiment, after 1 hour and every hour up to the end of the experiment (objective death of the uterus) were analyzed. Additional evaluation of the data was carried out using the Origin program (OriginLab version 8.5; OriginLab Corporation, Northampton, Massachusetts, USA).

Absolute maximum pressures (IUP) and areas under the curve (AUCs) were calculated. The amount of the AUC, as the total of all pressure values measured over a specific time interval, represented the work performed and output of the myometrium. In addition, the relative or effective contraction time (= contraction time/perfusion time) was calculated. The number of contractions per time interval was evaluated as the contraction frequency (F). The time from beginning of measurable contractions to the point of absence of measurable uterine contractions or absence of rhythmic contractions was calculated as survival time in hours.

\section{Statistics}

The data calculated by the Origin program were further analyzed statistically using Microsoft Excel and SPSS (IBM SPSS Statistics, version 19.0.0.1). Group comparisons were carried out after checking for normal distribution, the prerequisites applying in each case, the scale level of each of the attributes analyzed and the corresponding test situation, using the Mann-Whitney $U$ test and the Kruskal-Wallis test or one-way analysis of variance (significance level $P=0.05$; post-hoc $P=0.017$ ). In the post-hoc procedure, the Tukey and Tamhane test was applied, depending on the results of tests for variance homogeneity and the test procedures previously used.

\section{Experimental procedure}

The uteri were divided into three groups for the experiment (Table 1):

- In group 1, 11 uteri were perfused with conventional KRBB.

- In group 2, eight uteri were perfused with the modified KRBB. In addition, excess perfusate was drained in the basin in this group.

- In group 3, 11 uteri were also perfused with the modified KRBB. In addition, the collected perfusate was drained from the organ basin approximately every $2 \mathrm{~h}$ physically, using gravity, and replaced with fresh medium.

\section{Induction of rhythmic uterine contractions}

To achieve optimal saturation of the uterus with oxygen, nutrients, and electrolytes, the initial perfusion was maintained for approximately 1 hour. If no spontaneous uterine contractions were recorded during this phase, oxytocin (Syntocinon $^{\circledR} \quad 10 \mathrm{IU}=50 \mathrm{mg} / \mathrm{mL}$; Novartis Pharma, Nuremberg, Germany) was administered as a bolus through the tube system at increasing dosages of $0.1 \mathrm{IU}, 0.5 \mathrm{IU}$, and $1 \mathrm{IU}$ at intervals of $15 \mathrm{~min}$ each until rhythmic contractions were induced [11]. If rhythmic contractions were still not observed, the experiment was stopped.

\section{Vitality parameters}

At the start of the experimental series and at 1-hour intervals, measurements of vitality parameters were made in all of the organs using the blood gas analysis device (ABL 800 Flex; Radiometer Ltd., Willich, Germany). $\mathrm{pH}$ and lactate were measured from venous drainage fluid.

\section{End of the experiment}

The end point of each experiment was defined as the absence of measurable uterine contractions or absence of rhythmic contractions after administration of oxytocin 
boluses at increasing dosages of $0.1 \mathrm{IU}, 0.5 \mathrm{IU}$, and $1 \mathrm{IU}$ at intervals of 15 min each.

\section{Results}

A total of 30 uteri were perfused. The mean weight of the organs was $152 \mathrm{~g}$ (range 75-200 g, median $160 \mathrm{~g}$ ).

\section{Group 1: KRBB}

A total of 11 uteri, with a mean initial weight of $168 \mathrm{~g}$ (range 130-200 g, median $170 \mathrm{~g}$ ), were perfused with conventional KRBB (Table 1). Initial rhythmic contractions were induced using oxytocin in all of the organs. The mean pressures were $2.37 \mathrm{mmHg}$ at IUP1 and $1.86 \mathrm{mmHg}$ at IUP2 (Figure 4). The mean AUC1 and AUC2 were $78.15 \mathrm{mmHg}$ and $48.11 \mathrm{mmHg}$, respectively (Figure 5). The mean frequency 1 (F1) was 6.0 contractions and the mean frequency 2 (F2) was 5.1 contractions per time interval (Figure 6). Macroscopically visible contractions were seen on average after a latency period of $2.35 \mathrm{~h}$. The mean survival time was $9.3 \mathrm{~h}$ (range $7-11 \mathrm{~h}$, median $9 \mathrm{~h}$ ). The organs' effective contraction time showed a mean of $6.95 \mathrm{~h}-$ i.e., contractions occurred during $75 \%$ of the perfusion time (Figure 7). The mean $\mathrm{pH}$ value after 1 hour of perfusion was 7.6, changing to 6.9 up to the end of the perfusion period (Figure 8). The mean lactate value correspondingly increased from $1.43 \mathrm{mmol} / \mathrm{L}$ to $4.1 \mathrm{mmol} / \mathrm{L}$ (Figure 9).

\section{Group 2: modified KRBB}

A total of eight uteri, with a mean initial weight of $147 \mathrm{~g}$ (range 70-200 g, median $160 \mathrm{~g}$ ), were perfused with the modified KRBB. Initial contractions were induced in two organs using oxytocin. The mean pressures were $6.9 \mathrm{mmHg}$ at IUP1 and $5.1 \mathrm{mmHg}$ at IUP2 (Figure 4). The mean AUC1 was $335.3 \mathrm{mmHg}$ and the mean AUC2 was $297.4 \mathrm{mmHg}$ (Figure 5). The mean F1 and F2 were 8.13 and 8.19 contractions per time interval, respectively

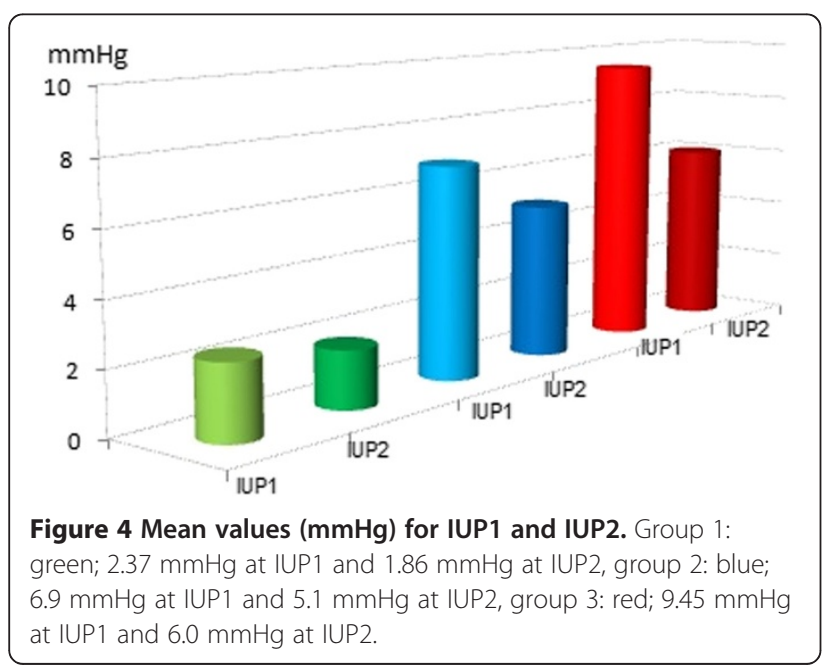

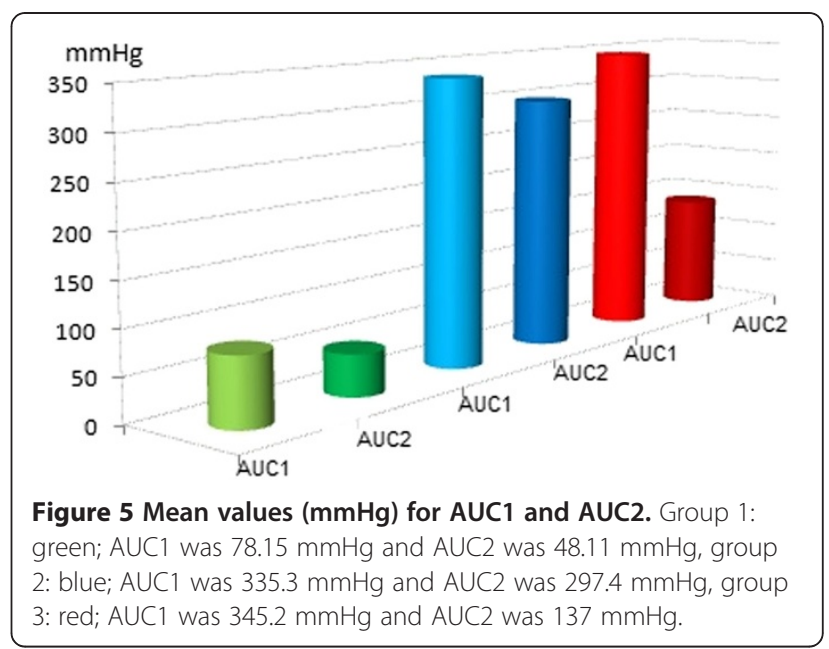

(Figure 6). Macroscopically visible contractions started on average after a latency period of 1.4 hours. The mean survival time was 8.13 hours (range 6-11 h, median $8 \mathrm{~h}$ ). The organs' effective contraction time showed a mean of $6.73 \mathrm{~h}-$ i.e., contractions took place during $83 \%$ of the perfusion period (Figure 7). The mean $\mathrm{pH}$ value after $1 \mathrm{~h}$ was 7.54 , changing to 7.0 up to the end of the perfusion period (Figure 8). The mean lactate value correspondingly increased from $1.7 \mathrm{mmol} / \mathrm{L}$ to $4.6 \mathrm{mmol} / \mathrm{L}$ (Figure 9).

\section{Group 3: modified KRBB and substitution of the total} perfusate in the organ basin with fresh perfusion medium A total of 11 uteri, with a mean initial weight of $143.5 \mathrm{~g}$ (range 75-200 g, median $145 \mathrm{~g}$ ), were perfused with the modified KRBB (Table 1) and in addition the perfusate collected in the organ basin was completely replaced with fresh medium approximately every 2 hours. In this group it was not necessary to induce initial contractions by oxytocin. The mean pressure values were $9.45 \mathrm{mmHg}$ at IUP1 and $6.0 \mathrm{mmHg}$ at IUP2 (Figure 4). The mean AUC1 was $345.2 \mathrm{mmHg}$ and the mean AUC2 was $137 \mathrm{mmHg}$ (Figure 5). The mean F1 and F2 were 12.7 and 10.2 contractions per time interval, respectively (Figure 6). Macroscopically visible contractions were visible after a mean latency period of 0.3 hours. The survival time was $13.3 \mathrm{~h}$ (range 10-17 h). The organs' effective contraction time averaged $13 \mathrm{~h}-$ i.e., contractions took place during $98 \%$ of the perfusion period. The mean $\mathrm{pH}$ value was 7.6 after 1 hour and it remained constant at 7.4 up to the end of the perfusion period (Figure 8). The mean lactate value increased from $1.27 \mathrm{mmol} / \mathrm{L}$ to $2.0 \mathrm{mmol} / \mathrm{L}$ (Figure 9).

\section{Statistically evaluation of the data}

Significantly different values for the contraction parameters IUP, AUC, and F were seen in each case in groups 2 and 3 


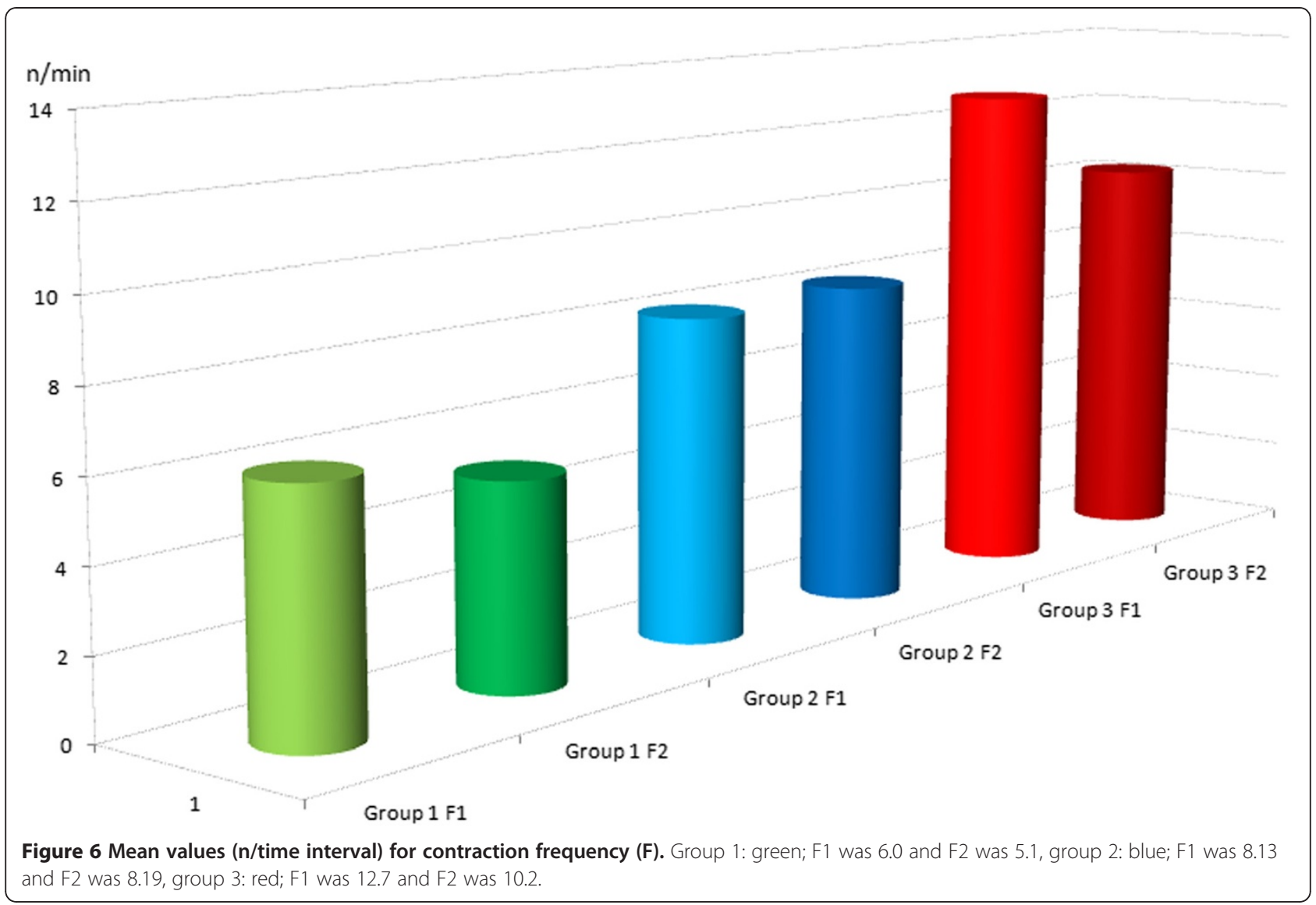

in comparison with perfusion using conventional KRBB in group 1 (Table 2). Initial rhythmic contractions were already observed after perfusion with the modified KRBB after 1.4 h (group 2) and after $0.3 \mathrm{~h}$ (group 3). In both group 1 and group 2, a clear increase in lactate and a decline in the $\mathrm{pH}$ value occurred during the course of the experiment. In group 3, regular substitution of the entire drained perfusate with fresh nutrient medium led to maintenance of a constant acid-base balance. This was reflected in significant differences in lactate and $\mathrm{pH}$ values in comparison with group 1 ( $P=0.005$ and $P<0.001$, respectively). The survival time in group 3 of up to 17 hours (mean $13.3 \mathrm{~h}$, median $13.5 \mathrm{~h}$ ), with a $98 \%$ proportion of effective contraction time, was significantly different from group 1

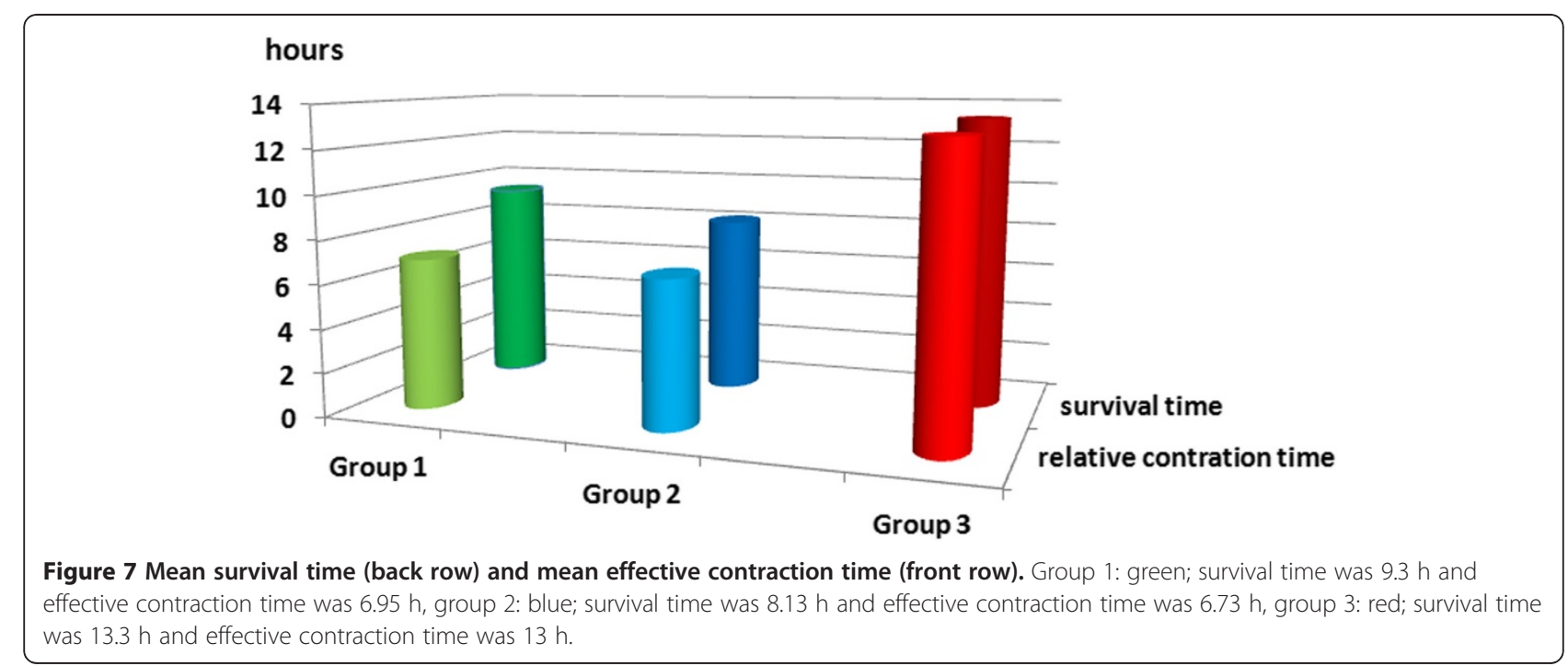




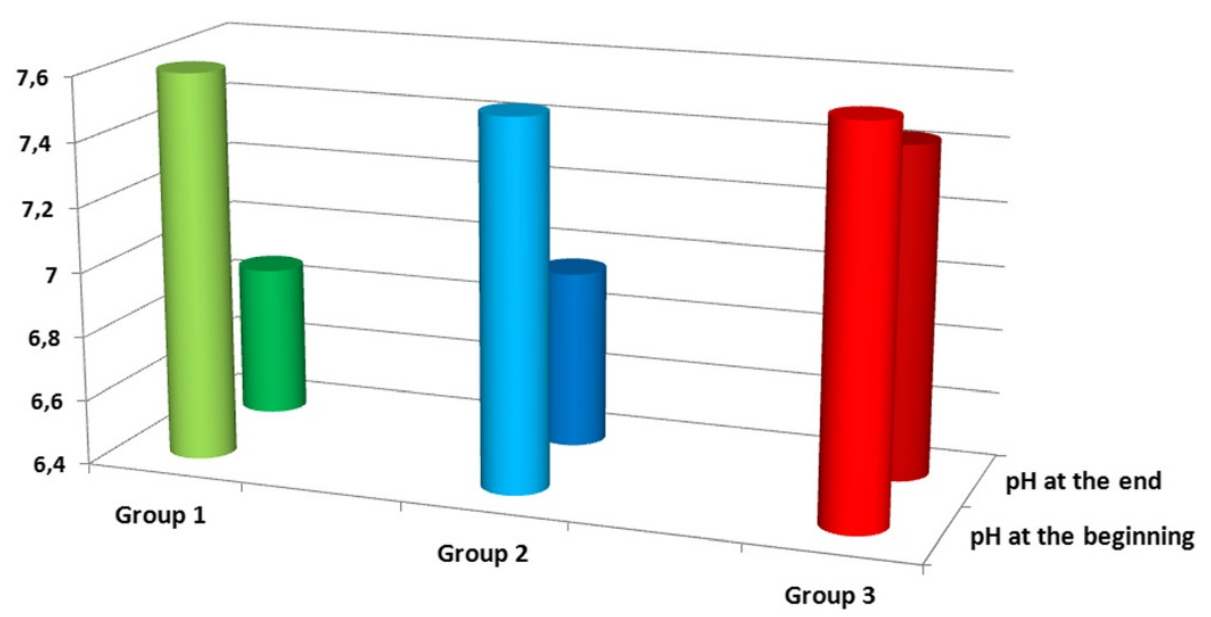

Figure 8 Mean $\mathrm{pH}$ values after $1 \mathrm{~h}$ perfusion (front row) and at the end of the experiment (back row). Group 1: green; pH after 1 hour was 7.6, changing to 6.9 up to the end, group 2: blue; $\mathrm{pH}$ after $1 \mathrm{~h}$ was 7.54, changing to 7.0 up to the end, group 3: red; pH was 7.6 after 1 hour and it remained constant at 7.4 up to the end.

$(P<0.001)$. The $P$ values are shown in Table 2 as the results of the group comparisons for the parameters studied and taking each test procedure into account.

\section{Discussion}

Adequate uterine contractility and an intact uterotubal transport process are necessary on the one hand for the transport of semen and gametes and also for successful spontaneous or assisted implantation of the embryo. On the other hand, inadequate uterine activity can lead to ectopic pregnancy, a tendency to spontaneous abortion, retrograde bleeding, and endometriosis [20-22]. As mentioned above, our research group has since 2003 therefore been focusing on functional studies of the perfused swine uterus [11]. The open perfusion model makes it possible to measure spontaneous and initiate contractions in the uterine horn and the body of the uterus using a double-chip microcatheter. In a large number of swine uteri, it has been possible to apply agents and medications such as oxytocin, tocolytics, spasmolytics, estrogen, progesterone, prostaglandins and seminal plasma and to examine their effects on the myometrium [11-14,23]. The bicornate swine uterus is particularly suitable for parallel experiments in the same genomic organ - for example, to evaluate transport mechanisms to the side bearing the dominant follicle [15]. The perfusion medium used to date was a standardized $\mathrm{KRBB}$, with which an experimentation period in physiological conditions of up to a maximum of 8 hours was

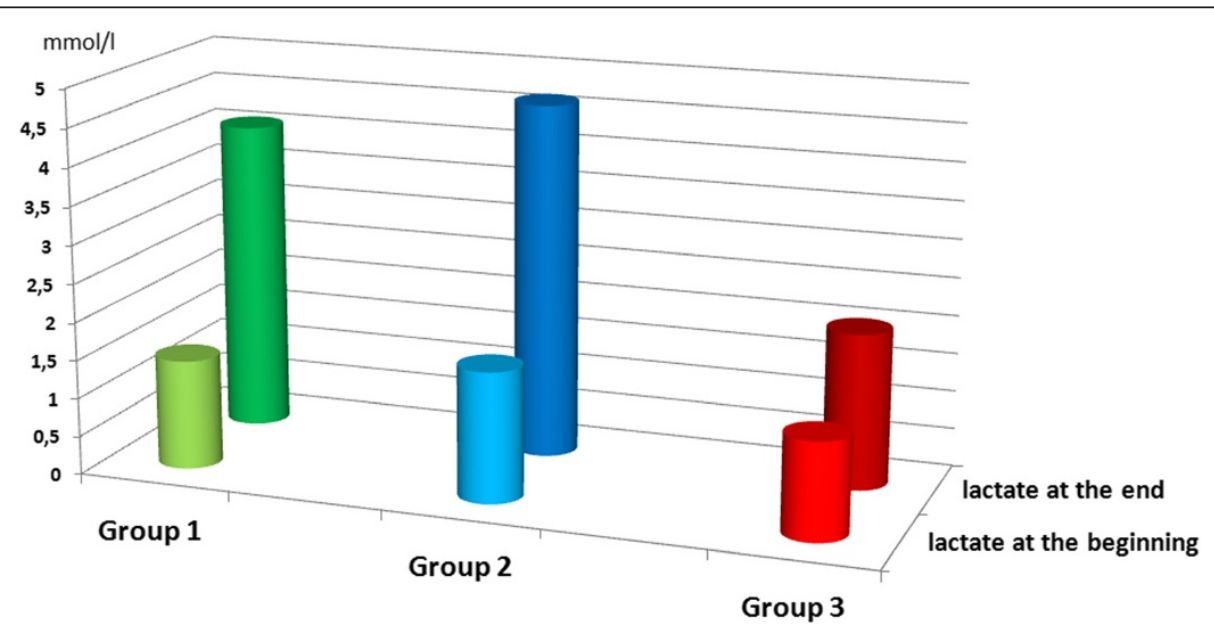

Figure 9 Mean lactate values ( $\mathrm{mmol} / \mathrm{L}$ ) after $1 \mathrm{~h}$ perfusion (front row) and at the end of the experiment (back row). Group 1: green; lactate increased from $1.43 \mathrm{mmol} / \mathrm{L}$ to $4.1 \mathrm{mmol} / \mathrm{L}$, group 2: blue; lactate increased from $1.7 \mathrm{mmol} / \mathrm{L}$ to $4.6 \mathrm{mmol} / \mathrm{L}$, group 3 : red; lactate increased from $1.27 \mathrm{mmol} / \mathrm{L}$ to $2.0 \mathrm{mmol} / \mathrm{L}$. 
Table 2 Group comparisons for the parameters studied; significant values are shown in bold type

\begin{tabular}{|c|c|c|c|}
\hline & $\begin{array}{c}\text { Group } 1 \text { vs. } \\
\text { Group } 2\end{array}$ & $\begin{array}{c}\text { Group } 1 \text { vs. } \\
\text { Group } 3\end{array}$ & $\begin{array}{c}\text { Group } 2 \text { vs. } \\
\text { Group } 3\end{array}$ \\
\hline IUP1 $(\mathrm{mmHg})^{a}$ & $P=0.015$ & $P<0.001$ & $P=0.220$ \\
\hline IUP2 $(\mathrm{mmHg})^{a}$ & $P=0.073$ & $P=0.002$ & $P=0.397$ \\
\hline AUC1 (mmHg/time) ${ }^{a}$ & $P=0.002$ & $P=0.001$ & $P=0.703$ \\
\hline$\overline{\text { AUC2 }(\mathrm{mmHg} / \text { time })^{a}}$ & $P<0.001$ & $P=0.007$ & $P=0.379$ \\
\hline F1 (contractions/time) ${ }^{a}$ & $P=0.001$ & $P<0.001$ & $P<0.001$ \\
\hline F2 (contractions/time) ${ }^{a}$ & $P<0.001$ & $P<0.001$ & $P=0.031$ \\
\hline Lactate start-end $(\mathrm{mmol} / \mathrm{L})^{\mathrm{b}}$ & $P=0.953$ & $P=0.005$ & $P=0.020$ \\
\hline $\mathrm{pH}_{\text {start-end }}{ }^{\mathrm{b}}$ & $P=0.461$ & $P<0.001$ & $P=0.008$ \\
\hline Survival $^{c}$ & $P=0.149$ & $P<0.001$ & $P=0.031$ \\
\hline
\end{tabular}

a Mann-Whitney $U$ test.

${ }^{\mathrm{b}}$ One-way analysis of variance + post-hoc.

c Kruskal-Wallis test.

possible (Table 1) [11]. The applicability of perfusion models for experimental studies of placental tissue, ovaries, and uteri has been repeatedly emphasized in the literature $[7,24,25]$.

In the present study, the open perfusion model previously described was to be further developed in order to make it possible in the future to study metabolic receptor ligands such as M3 cholinergic receptors in long-term perfusion of the ex vivo swine uterus. Methods of conserving the organ with hypothermia have severe limitations in connection with metabolic studies, since among other things they lead to inactivation of transmembrane ion pumps [16]. In experimental and clinical transplantation medicine, various solutions have been used for cold conservation of organs, such as Euro-Collins solution, University of Wisconsin solution, histidine-tryptophane-ketoglutarate solution, and HypoThermosol [19,26-30]. Successful use of KRBB for perfusion of human and porcine uteri has been described in many previous literature reports $[8,11,16]$. As in the studies by Bulletti et al. [8] and Richter et al. [16], a modified KRBB was used for experimental long-term perfusion of swine uteri in the present study.

In comparison with the perfusion system used by Richter et al. [16], with recirculation of the nutrient medium, the open variant of the perfusion system is more cost-effective. It is not necessary to use a membrane oxygenator and an incubator for the experiment. The perfusion medium is continuously oxygenated and the swine uterus is surrounded by nutrient medium in the organ basin. The open perfusion system, consisting of an organ basin, roller pump with infusion system, gas bottle, and shaking bath, as well as software and hardware, can be quickly and effortlessly set up and operated by one person. The use of swine uteri for perfusion experiments is appropriate, as discussed in the introduction, and the results are comparable with human conditions. The logistic effort involved in obtaining the swine uteri is much lower in comparison with perfusion of human uteri, allowing a larger number of organs to be studied in a shorter time. When the perfusate is recirculated, as described by Richter et al. [16], perfusion medium can be saved. With this method, it is nevertheless still necessary to completely replace approximately $2 \mathrm{~L}$ of perfusion medium after 4 hours [18]. In the open perfusion model described here, approximately $1.5 \mathrm{~L} / \mathrm{h}$ is consumed with a flow rate of around $15 \mathrm{~mL} / \mathrm{min}$ and complete substitution of the basin perfusate with $1 \mathrm{~L}$ of fresh medium every $2 \mathrm{~h}$. This corresponds to a perfusion medium consumption of approximately $6 \mathrm{~L}$ every $4 \mathrm{~h}$, around three times the amount in comparison with the study by Richter et al. [16]. It should be taken into account here that direct comparison of perfusion medium consumption between human and swine uteri is only possible to a limited extent, due to the different size of the organs. Although the greater consumption of perfusion medium is a disadvantage of the open model, it is quite acceptable in view of other cost savings. Producing the modified KRBB is inexpensive, uncomplicated, and takes little time. Relevant bacterial infection of the organ during the experiment has been assessed as minimal, and antibiotic prophylaxis was not therefore used.

As mentioned earlier, a maximum perfusion time of $8 \mathrm{~h}$ has been achieved to date with the standardized form of KRBB [11]. The results of the present study show that using the modified KRBB can significantly prolong the survival time of swine uteri from a maximum of $11 \mathrm{~h}$ (in group 1) to a maximum of $17 \mathrm{~h}$ (group 3). Against the background of the results reported by Bulletti et al. [8] and Richter et al. [16] with regard to long-term perfusion of human uteri, the aim of maintaining the vitality of swine uteri for $24 \mathrm{~h}$ was not achieved. Nevertheless, a mean survival time of $13.3 \mathrm{~h}$ in group 3 , with a maximum survival time of up to $17 \mathrm{~h}$, now appears capable of permitting more detailed metabolic and physiological studies of the swine uterus. The physiology of the swine uterus is very similar to that of the human uterus, although not identical, so that only limited direct comparison of the survival times reported in the literature is possible. The results show that a combination of modified KRBB and substitution of the entire perfusate in the organ basin appears to be necessary in order to achieve a significant increase in the survival time. In the present study the vitality parameters, $\mathrm{pH}$ and lactate, were measured from venous drainage fluid, which is an accurate method to monitor the physiologic condition of the organ [11]. But to investigate the impact of long term perfusion on a cellular level it would be necessary to take biopsies at the beginning and at the end of the experiment.

Significantly better contraction parameters (IUP, AUC, F) were already observed using perfusion with modified KRBB in group 2 in comparison with conventional KRBB in 
group 1 (Table 2). In addition, the modified KRBB in comparison with conventional KRBB usually led to the initiation of spontaneous contractions after a short latency period and with a much longer effective contraction period (Figure 7). In practice, this means that on the one hand a marked time saving is possible due to the shorter latency period ( $2.35 \mathrm{~h}$ in group $1 \mathrm{vs.} 0.3 \mathrm{~h}$ in group 3 ) before the start of spontaneous contraction of the organs, while on the other hand the quality of the perfusion experiments is also improved.

\section{Conclusions}

In summary, the use of the modified KRBB in combination with substitution of the basin perfusate led to a marked improvement in survival time and in the quality of the contraction parameters in swine uteri in the open perfusion model. In the future, this model can be used for medium-term to long-term perfusion in more detailed metabolic perfusion experiments, with little logistic effort and at low cost.

\section{Abbreviations}

AUC: Area under the curve; F: Frequency (of contractions); IUP: Intrauterine pressure; KRBB: Krebs-Ringer bicarbonate buffer (solution).

\section{Competing interests}

The authors declare that they have no competing interests.

\section{Authors' contributions}

KG and RD have made substantial contributions to conception and design and were responsible for acquisition of data. PG and KG were responsible for analysis and interpretation of data. JK, MWB and AM have been revising the manuscript critically for important intellectual content. MWB and RD has given final approval of the version to be published. MWB was supervisor of the present study. All authors read and approved the final manuscript.

Received: 10 October 2012 Accepted: 13 December 2012

Published: 15 December 2012

\section{References}

1. Toledo-Pereyra LH: Pulsatile perfusion is still indicated for kidney preservation. Transplantation 1982, 34:110.

2. Kamada N, Calne RY, Wight DG, Lines JG: Orthotopic rat liver transplantation after long-term preservation by continuous perfusion with fluorocarbon emulsion. Transplantation 1980, 30:43-48.

3. van der Wijk J, Slooff MJ, Rijkmans BG, Kootstra G: Successful 96- and 144-hour experimental kidney preservation: a combination of standard machine preservation and newly developed normothermic ex vivo perfusion. Cryobiology 1980, 17:473-477.

4. Baldan N, Toffano M, Cadrobbi R, Codello L, Calabrese F, Bacelle L, Rigotti P: Kidney preservation in pigs using Celsior, a new organ preservation solution. Transplant Proc 1997, 29:3539-3540.

5. Ohura H, Kondo T, Handa M, Saito R, Matsumura Y, Okada Y, Shimada K, Hirose M, Horikoshi A, Sugita M, et al: Functional and histopathologic studies of primate pulmonary allografts preserved for 24 hours with form of modified extracellular solution. J Heart Lung Transplant 1995, 14:493-504.

6. Iwasaki S, Araki H, Miyauchi Y, Nishi K: 24-hour preservation of isolated rat hearts perfused with pyridoxalated hemoglobin polyoxyethylene conjugate (PHP) solution at low temperature. Artif Organs 1991, 15:78-85.

7. Bulletti C, Jasonni VM, Lubicz S, Flamigni C, Gurpide E: Extracorporeal perfusion of the human uterus. Am J Obstet Gynecol 1986, 154:683-688.
8. Bulletti C, Jasonni VM, Tabanelli S, Gianaroli L, Ciotti PM, Ferraretti AP, Flamigni C: Early human pregnancy in vitro utilizing an artificially perfused uterus. Fertil Steril 1988, 49:991-996.

9. Bulletti C, de Ziegler D, Polli V, Diotallevi L, Del Ferro E, Flamigni C: Uterine contractility during the menstrual cycle. Hum Reprod 2000, 15(Suppl 1):81-89.

10. Bulletti C, Jasonni VM, Martinelli G, Govoni E, Tabanelli S, Ciotti PM, Flamigni C: A 48-hour preservation of an isolated human uterus: endometrial responses to sex steroids. Fertil Steril 1987, 47:122-129.

11. Dittrich R, Maltaris T, Müller A, Dragonas C, Scalera F, Beckmann MW: The extracorporeal perfusion of swine uterus as an experimental model: the effect of oxytocic drugs. Horm Metab Res 2003, 35:517-522.

12. Mueller A, Siemer J, Schreiner S, Koesztner H, Hoffmann I, Binder H, Beckmann MW, Dittrich R: Role of estrogen and progesterone in the regulation of uterine peristalsis: results from perfused non-pregnant swine uteri. Hum Reprod 2006, 21:1863-1868.

13. Mueller A, Maltaris T, Siemer J, Binder H, Hoffmann I, Beckmann MW, Dittrich $R$ : Uterine contractility in response to different prostaglandins: results from extracorporeally perfused non-pregnant swine uteri. Hum Reprod 2006, 21:2000-2005.

14. Künzel J, Geisler K, Hoffmann I, Müller A, Beckmann MW, Dittrich R. Myometrial response to neurotropic and musculotropic spasmolytic drugs in an extracorporeal perfusion model of swine uteri. Reprod Biomed Online 2011, 23:132-140.

15. Mueller A, Siemer J, Renner S, Hoffmann I, Maltaris T, Binder H, Beckmann MW, Dittrich R: Perfused non-pregnant swine uteri: a model for evaluating transport mechanisms to the side bearing the dominant follicle in humans. J Reprod Dev 2006, 52:617-624.

16. Richter O, Wardelmann E, Dombrowski F, Schneider C, Kiel R, Wilhelm K, Schmolling J, Kupka M, van der Ven H, Krebs D: Extracorporeal perfusion of the human uterus as an experimental model in gynaecology and reproductive medicine. Hum Reprod 2000, 15:1235-1240.

17. Maltaris T, Dragonas C, Hoffmann I, Mueller A, Schild RL, Schmidt W, Beckmann MW, Dittrich R: The extracorporeal perfusion of the swine uterus as an experimental model: the effect of tocolytic drugs. Eur J Obstet Gynecol Reprod Biol 2006, 126:56-62.

18. Kim SY: Extrakorporale Uterusperfusion zur Untersuchung von Uterotonika in der Geburtshilfe und Reproduktionsmedizin [doctoral dissertation]. Bonn: University of Bonn; 2006. Available at: http://hss.ulb.uni-bonn.de/2006/0687/ 0687.pdf.

19. Southard JH, Belzer FO: Organ preservation. Annu Rev Med 1995, 46:235-247.

20. Bulletti C, De Ziegler D, Polli V, Del Ferro E, Palini S, Flamigni C: Characteristics of uterine contractility during menses in women with mild to moderate endometriosis. Fertil Steril 2002, 77:1156-1161.

21. Bulletti C, de Ziegler D: Uterine contractility and embryo implantation. Curr Opin Obstet Gynecol 2005, 17:265-276. Corrected and republished in: Curr Opin Obstet Gynecol 2006, 18:473-484.

22. Kissler S, Siebzehnruebl E, Kohl J, Mueller A, Hamscho N, Gaetje R, Ahr A, Rody A, Kaufmann M: Uterine contractility and directed sperm transport assessed by hysterosalpingoscintigraphy (HSSG) and intrauterine pressure (IUP) measurement. Acta Obstet Gynecol Scand 2004, 83:369-374.

23. Dittrich R, Henning J, Maltaris T, Hoffmann I, Oppelt PG, Cupisti S, Beckmann MW, Mueller A, Kiesewetter F: Extracorporeal perfusion of the swine uterus: effect of human seminal plasma. Andrologia 2012, 44(Suppl 1):543-549.

24. Page KR: Perfusion of isolated human placenta. Proc Nutr Soc 1991 50:345-347.

25. Brännström M, Flaherty S: Methodology and characterization of an in vitro perfusion model for the mouse ovary. J Reprod Fertil 1995, 105:177-183.

26. Bellamy CA, Nicely B, Mattice BJ, Teaster R: Comparative analysis of clinical efficacy and cost between University of Wisconsin solution and histidine-tryptophan-ketoglutarate. Prog Transplant 2008, 18:166-171. quiz 172.

27. Hrabalová M, Bachleda P, Lubuská L, Kojecký Z, Zadrazil J, Krejcí K, Al Jabry S: Effect of various protective solutions on function after kidney transplantation. Biomed Pap Med Fac Univ Palacky Olomouc Czech Repub 2003, 147:197-202. 
28. Bessems M, Doorschodt BM, van Vliet AK, van Gulik TM: Preservation of rat livers by cold storage: a comparison between the University of

Wisconsin solution and Hypothermosol. Ann Transplant 2004, 9:35-37.

29. Collins GM, Wicomb WN: New organ preservation solutions. Kidney Int Supp/ 1992, 38:S197-202.

30. Collins GM: What solutions are best? Overview of flush solutions. Transplant Proc 1997, 29:3543-3544.

doi:10.1186/1477-7827-10-110

Cite this article as: Geisler et al:: The perfused swine uterus model: longterm perfusion. Reproductive Biology and Endocrinology 2012 10:110.

\section{Submit your next manuscript to BioMed Central and take full advantage of:}

- Convenient online submission

- Thorough peer review

- No space constraints or color figure charges

- Immediate publication on acceptance

- Inclusion in PubMed, CAS, Scopus and Google Scholar

- Research which is freely available for redistribution 